\title{
HUBUNGAN INTENSITAS SUARA DAN MASA KERJA DENGAN KELUHAN PENDENGARAN PEKERJA FINISHING PT. PUNDI INDOKAYU INDUSTRI KECAMATAN KALIBAGOR KABUPATEN BANYUMAS TAHUN 2016
}

\author{
Karina Pravi Jayanti ${ }^{1}$, Hari Rudijanto ${ }^{2}$, Sugeng Abdullah ${ }^{3}$ \\ Jurusan Kesehatan Lingkungan, Politeknik Kesehatan Kemenkes Semarang, \\ Jl.Raya Baturaden KM 12 Purwokerto, Indonesia
}

\begin{abstract}
Abstrak
Latar Belakang Tenaga kerja sebagai sumber daya manusia, perlu mendapat perhatian khusus baik kemampuan, keselamatan, maupun kesehatan kerjanya. Tujuan penelitian untuk memperoleh gambaran hubungan intensitas suara dan masa kerja mesin finishing dengan keluhan pendengaran pekerja. Jenis penelitian observasi analitik dengan pendekatan crossectional.,variabel bebasnya adalah intensitas suara dan masa kerja,sedangkan variabel terikatnya adalah keluhan pendengaran. Hasil penelitian diketahui intensitas suara pada posisi pekerja bekerja dengan mesin finishing terdapat 8 titik yang tidak memenuhi syarat ( > 85 dBA ).Masa kerja semua pekerja masih pada usia produktif. Jenis keluhan yang dialami pekerja yaitu telinga berdenging, percakapan diulang dan gangguan komunikasi. Disimpulkan tidak ada hubungan antara intensitas suara dan masa kerja dengan keluhan pendengaran pekerja finishing PT. Pundi Indokayu Industri Kecamatan Kalibagor Kabupaten Banyumas. Disarankan untuk menyediakan earplug bagi pekerja dan untuk penelitian selanjutnya menggunakan audiometri untuk pengukuran keluhan pendengaran.
\end{abstract}

Kata kunci : $\quad$ intensitas suara, masa kerja dan keluhan pendengaran

Abstract

(Correlation between noise intensity and Length of Service with Finishing Workers Hearing Interference At PT. Pundi Indokayu Industry, Kalibagor Districts Banyumas Regency Year of 2016). Labor as human resources needs special attention for its capability, safety, and health. The research objective was obtaining brief description about the correlation between noise intensity and length of service with workers hearing interference. The research method used was observational analytic research with crosssectional approach, the independent variable was hearing interfence. The research results shows that there are 8 point in the finishing department that impinge the applied standart (> $85 \mathrm{dBA}$ ), this means that all workers are still in their productive age. The type of interfece suffered was buzzing ears, repeated conversations and communication disorders. The conclusions drawn based statistical tst results using double regression $p=0,178>\alpha(0,05)$ and $p=0,416>\alpha(0,05)$. This means that there is no correlation between noise intensity and length of service with hearing interference at finishing department of PT. Pundi Indokayu Industry Kalibagor District Banyumas Regency. The proposed suggestion was to provide earplug for workers and future researcher should use audiometry for measuring hearing interference.

Keywords : Noise intensity, Length of Service and Hearing Interference

\footnotetext{
${ }^{1}$ Email : karina.pravijayanti@yahoo.com

${ }^{2}$ Email : hariokey2000@yahoo.com

${ }^{3}$ Email : sugengzend@gmail.com
} 


\section{PENDAHULUAN}

Tenaga kerja sebagai sumber daya manusia, perlu mendapat perhatian khusus baik kemampuan, keselamatan, maupun kesehatan kerjanya. Upaya perlindungan tenaga kerja perlu diterapkan karena berhubungan kesehatan tenaga kerja. Pengelolaan lingkungan kerja dapat mendukung pemeliharaan dan peningkatan kesehatan tenaga kerja sehingga terselenggara dengan baik (Budiono, 2007). Resiko bahaya yang dihadapi oleh tenaga kerja adalah bahaya kecelakaan dan penyakit akibat kerja, akibat kombinasi dari berbagai faktor yaitu tenaga kerja dan lingkungan kerja (Suma'mur, 2009)

Sebuah pabrik biasanya memiliki beberapa mesin untuk menjalankan proses produksinya. Pada saat bekerja, mesin tersebut biasanya mengeluarkan bunyi yang memungkinkan terjadinya kebisingan. Konsentrasi dalam bekerja dapat menurun, bahkan jika kebisingan terjadi dalam intensitas yang sangat tinggi dapat menyebabkan pengaruh yang buruk bagi para pekerja, hal ini sangat mengganggu kinerja karyawan pabrik karena dapat menurunkan produktivitas kerjanya dan menyebabkan perusahaan mengalami kerugian.

Pada kawasan Asia Tenggara terdapat 75 sampai 140 juta jiwa menderita gangguan pendengaran. Prevalensi gangguan pendengaran pada populasi penduduk Indonesia sendiri diperkirakan sebesar 4,6\% (Soetjipto, 2007). Sebuah hasil penelitian yang dilakukan pada pekerja produksi di PT.Pertamina RU VII Kasim Sorong tahun 2013. Hasil yang diperoleh 61,76\% pekerja mengalami ganguan pendengaran pada telinga kanan dan $14,7 \%$ pada telinga kiri (Heinsye F.Loblobly ,Ricky C. Sondakh,Johan Josephus, 2013).

Intensitas suara di tempat kerja bukan hanya menyebabkan gangguan pendengaran seperti penurunan nilai ambang batas dengar pekerja, namun juga dapat menyebabkan gangguan nonaudiotoir (gangguan yang tidak berpengaruh langsung terhadap pendengaran) yaitu stress, mempercepat denyut nadi, meningkatkan tekanan darah, perasaan mudah marah, gangguan komunikasi, dan menurunkan gairah kerja yang akan menyebabkan meningkatnya absensi.
PT. Pundi Indokayu Industri merupakan salah satu industry di bidang pengolahan kayu, produk dari perusahaan ini adalah Ply Wood. Proses yang berlangsung meliputi rotary, spindle, dry press, glue spryder, cold press, sander, sizer, dan packing. Penggunaan peralatan dan tekhnologi modern dalam proses produksi memberikan dampak sangat positif, berupa terciptanya efisiensi dan produktivitas kerja. Akan tetapi di sisi lain juga menimbulkan dampak negatif berupa resiko bahaya bagi tenaga kerja.

Pada bagian sander dan sizer atau biasa di sebut bagian finishing mesin bekerja selama 24 jam, hal ini tentu saja menimbulkan resiko kebisingan pada saat proses produksi. Resiko kebisingan berdampak pada pendengaran para pekerja. Berdasarkan data yang sudah ada pada tahun 2015 dilakukan penelitian oleh Hiperkes Semarang yang hasilnya tingkat kebisingan pada bagian finishing adalah antara 88 sampai dengan $90 \mathrm{Db}$.

Tujuan penelitian ini adalah untuk menganalisis hubungan intensitas suara dan masa kerja dengan keluhan pendengaran pada pekerja finishing PT. Pundi Indokayu Industri Kecamatan Kalibagor Kabupaten Banyumas tahun 2016.

\section{BAHAN DAN METODE}

Dalam penelitian ini variabel bebasnya adalah intensitas suara dan masa kerja, variabel terikatnya adalah keluhan pendengaran. Variabel penganggunya adalah riwayat penyakit, laju udara, suhu, kelembaban, jarak mesin dan variabel kontrolnya adalah lama paparan mesin, dan APD. Jenis penelitian adalah penelitian observasi analitik dengan pendekatan crossectional. Lokasi penelitian di PT. Pundi Indokayu Industri yang berada di Kecamatan Kalibagor Kabupaten Banyumas.

Materi penelitian ini yang berhubungan dengan intensitas suara, masa kerja dan keluhan pendengaran di lingkungan kerja pada bagian produksi bagian finishing pabrik kayu PT. Pundi Indokayu Industri Kecamatan Kalibagor Kabupaten Banyumas. Populasi dalam penelitian ini adalah semua pekerja pada bagian finishing PT. Indokayu Industri sebanyak 10 orang, dan sampel yang diambil dalam penelitian ini adalah total populasi 10 orang. Data diperoleh denga cara observasi pengukuran dan wawancara yang dilakukan meliputi intensitas suara, masa kerja 
dan keluhan pendengaran pada pekerja bagian finishing PT. Pundi Indokayu Industri.

Cara Pengumpulan Data yang dilakukan :

a. Observasi dilakukan dengan melakukan pengamatan langsung terdapat objek yang diteliti dilingkungan kerja bagian finishing pabrik kayu PT. Pundi Indokayu Industri Kalibagor. Data observasi meliputi : kondisi perilaku pekerja, upaya pengendalian resiko paparan intesitas suara mesin pada para pekerja di bagian finishing pada PT Pundi Indokayu Industri.

b. Pembagian kuesioner dilakukan untuk memperoleh informasi yang dibutuhkan oleh penelitian dalam penyusunan skripsi kepada pekerja di bagian finishing pabrik kayu PT. Pundi Indokayu Industri Kalibagor. Data meliputi: keluhan pendengaran, masa kerja, APD yang disediakan PT. Pundi Indokayu Industri, upaya meminimalisir dampak pemaparan intensitas suara pada pekerja.

c. Wawancara yaitu dialog yang dilakukan oleh peneliti pada pekerja bagian finishing pabrik kayu PT. Pundi Indokayu Industri Kalibagor untuk memperoleh informasi yang dibutuhkan oleh peneliti dalam penyusunan skripsi. Data peneliti meliputi: sumber pemaparan intensitas suara terhadap pekerja seperti tempat tinggal pekerja, kebiasan perilaku pekerja.

d. Pengukuran, yaitu pengumpulan data dengan cara melakukan pengukuran objek yang ingin diketahui ukurannya, yaitu intensitas suara mesin.

e. Cheklist dilakukan untuk mengetahui kondisi lingkungan pada pabrik PT. Pundi Indokayu Industri. Data meliputi : penggunaan APD pada pekerja

\section{HASIL DAN PEMBAHASAN}

1. Proses bagian finishing PT. Pundi Indokayu Industri

a.Perekatan

Aplikasi peleburan perekatan pada kayu lapis dapat dilakukan dengan cara roller coater, cuartain coater, spry coater, atau liquid dan foam extruder.
b.Pengepresan (Cold Press dan Hot Press)

Sebagian besar kayu lapis diproduksi dengan menggunakan kempa panas. Besarnya tekanan berkisar antara 100-250 psi tergantung pada kerapatan kayunya.

c.Pengkondisian

Pengkondisian dilakukan bertujuan untuk mengurangi sisa tegangan atau tekanan akibat proses pengempaan serta menyesuaikan dengan kondisi lingkungan. Biasanya dilakukan selama 1-2 minggu.

2. Hasil Pengukuran Intensitas Suara di Bagian Finishing

Pengukuran di ruang finshing PT. Pundi Indokayu Industri dilakukan pada saat hari cerah dan pencahayaan yang cukup, ruang finishing terbuka.

Peraturan Menteri Tenaga Kerja Nomor 13 tahun 2011 tentang Nilai Ambang Batas Faktor Fisika dan Faktor Kimia di Tempat Kerja menyebutkan bahwa tingkat kebisingan diruang kerja maksimal $85 \mathrm{dBA}$ sedangkan hasil pengukuran pada pada 18 titik penelitian diketahui terdapat 10 titik yang tidak memenuhi syarat (> NAB $=85 \mathrm{dBA})$. Berdasarkan hasil pengukuran intensitas suara pada posisi pekerja bekerja dengan mesin finishing terdapat 8 titik yang tidak memenuhi syarat $(>\mathrm{NAB}=85 \mathrm{dBA})$.

Upaya yang dilakukan untuk meminimalisir kebisingan pada sumber bising yaitu dengan cara melakukan perawatan pada mesin dan pengecakan secara rutin. Hal ini bertujuan agar mesin dapat terawat dengan baik dan tidak mudah rusak. Pemisahan sumber bising dari pekerja misalnya meletakkan generator di tempat yang terpisah dari para pekerja bekerja, pemasangan peredam suara seperti, Acourete Fiber dan Acourete Board 230.Memasang ventilasi udara seperti exshauster, kipas blower 3. Masa Kerja Pekerja

Hasil peneliian terhadap 10 responden mendapati pekerja yang memiliki masa kerja antara 1-12 bulan berjumlah 4 pekerja, 4 pekerja yang sudah bekerja antara 13 - 24 bulan dan 2 pekerja yang sudah bekerja antara $25-36$ bulan. Masa kerja seorang pekerja akan 
mempengaruhi resiko keluhan pendengaran

Semakin lama seseorang bekerja pada tempat intensitas suara yang tinggi dan melebihi ambang batas maka akan semakin tinggi terkena gangguan kesehatan, terutama gangguan pendengaran. Hasil wawancara didapat masa kerja yang paling lama adalah 25-36 bulan dan yang baru yaitu 1-12bulan, sehingga pekerja yang memiliki masa kerja 25-36 bulan lebih berisko terkena gangguan kesehatan berupa gangguan pendengaran daripada pekerja yang baru memiliki masa kerja 1-12 bulan.

4. Keluhan Pendengaran Yang Dialami Pekerja

Menurut A.M Sugeng Budiono (2009, h.33) menjelaskan bahwa pengaruh kebisingan terhadap kesehatan adalah mengurangi kenyaman, menganggu komunikasi, mengurangi konsentrasi, menurunkan daya dengar atau tuli. Berdasarkan hasil kuesioner yang dilakukan pada 10 pekerja didapatkan 4 keluhan telinga berdenging, 4 keluhan percakapan diulang, dan 2 keluhan gangguan komunikasi, seperti merasa tidak jelas saat melakukan percakapan, mendengar orang lain yang sedang berbicara terdengar bergumam. Keluhan gangguan komunikasi terjadi apabila intensitas suara cukup keras (lebih besar dari $85 \mathrm{dBA}$ ), berlangsung lama dan kontinyu. Pada awalnya bersifat sementara tapi bila paparan bising terus berlangsung dengan intensitas yang tetap tinggi, dapat mengakibatkan gangguan pendengaran menetap. Keluhan percakapan yang diulang lebih banyak karena pekerja bekerja di ruang finshing secara terusmenerus sehingga beriseko terkena paparan dari sumber bising yang terusmenerus yaitu dari mesin sizer dan sander.

\section{Karateristik Pekerja}

Responden penelitian ini adalah pekerja finishing di PT. Pundi Indokayu
Indusrtri Kecamatan Kalibagor Kabupaten Banyumas, dengan total keseluruhan pekerja sebanyak: 10 orang. Karateristik pekerja meliputi umur pekerja, tingkat pendidikan, suhu dan kelembaban, dan laju udara. Data karateristik pekerja dikumpulkan melalui wawancara terhadap pekerja.

a. Umur Pekerja

Hasil wawancara diperoleh data umur pekerja yang produktif sebanyak 10 orang. Yang terdiri dari umur (2029) berjumlah 6 orang, umur (30-39) berjumlah 2 orang, umur (40-49) berjumlah 1 orang, dan umur (50-59) berjumlah 1 orang.

Menurut Undang-Undang Tenaga Kerja No.13 Tahun 2003, angkatan kerja adalah penduduk usia produktif yang berusia antara 15-64 tahun yang sudah mempunyai pekerjaan tetapi sementara tidak bekerja, maupun yang sedang aktif mencari pekerjaan. Berdasarkan hasil wawancara dari 10 responden, semua pekerja finishing PT. Pundi Indokayu Industri masih berusia produktif.

b. Tingkat Pendidikan

Hasil dari wawancara 10 responden didapatkan sebagian besar pekerja mempunyai tingkat pendidikan SMA yaitu sebanyak 8 pekerja, tingkat pendidikan SMP sebanyak 2 orang dan tidak ada yang lulusan SD dari 10 responden yang diteliti. Hal ini mempengaruhi pengetahuan terhadap penggunaan APD, sebagian besar aktivitas pekerja di ruang finishing selama bekerja menggunakan masker sebagai APD.

c. Suhu dan Kelembaban

Hasil dari pengukuran suhu dan kelembaban yang dilakukan pada pagi, siang dan sore hari didapatkan suhu pada pagi hari yaitu $29{ }^{\circ} \mathrm{C}$ dan kelembaban $62 \%$. Siang hari didapatkan suhu $31{ }^{\circ} \mathrm{C}$ dan kelembaban $70 \%$, sedangkan pada sore hari didapatkan suhu $31{ }^{\circ} \mathrm{C}$ dan kelembaban $70 \%$.

Berdasarkan Kepmenkes No. 1405/MENKES/SK/2002 tentang 
Peryaratan Kesehatan Lingkungan Kerja Perkantoran dan Industri, persyaratan suhu $18-28{ }^{\circ} \mathrm{C}$ sedangkan kelembaban sebesar 40-60\%, hal ini berarti suhu dan kelembaban pada ruang finishing belum memenuhi syarat. Apabila suhu udara tinggi maka tekanan udara pada ruang finishing juga tinggi hal ini berdampak pada produktifitas para pekerja, apabila suhu udara tinggi maka suhu akan lebih terasa panas dan menyebabkan pekerja lebih mudah lelah seperti terganggunya konsentrasi pada saat bekerja. Pada kelembaban udara yang tinggi, titiktitik air terkandung di udara akan mengurangi terjadinya gesekan saat ada gelombang bunyi yang merambat, sehingga penurunan kekuatan gelombang bunyi juga tidak besar, maka serapan yang lebih besar akan terjadi lebih baik pada udara dengan kelembaban yang rendah.( Sunarti, 2008)

d. Laju Udara

Hasil dari pengukuran laju udara yang dilakukan pada pagi, siang dan sore hari didapatkan pada pagi hari $0,09 \mathrm{~m} / \mathrm{s}$, pada siang hari $0,15 \mathrm{~m} / \mathrm{s}$ dan pada sore hari $0,09 \mathrm{~m} / \mathrm{s}$. Adanya udara bisa membawa getaran suara mesin lewat jalur udara. Laju udara dapat membawa sumber bising dari mesin ke manusia, hal ini sangat dipengaruhi oleh kecepatan dan arah angin. Pada kondisi angin bertiup dari sumber bunyi menuju suatu titik, maka titik tersebut akan menerima bunyi dengan lebih cepat, dalam kekuatan yang cukup besar. Namun sebaliknya, bila angin bertiup menuju arah yang berlawanan, menjauhi titik, maka titik tersebut akan menerima bunyi dengan kekuatan yang lemah.

Upaya yang dapat dilakukan adalah dengan menambah ventilasi udara, memasang exshauster, atau kipas blower.
6.Jenis Alat Pelindung Diri

Pengamatan yang dilakukan di ruang finishing PT. Pundi Indokayu Industri alat pelindung diri yang berupa alat pelindung telinga seperti ear muff dan earplug tidak disediakan. Sebagian dari para pekerja hanya menggunakan masker saja. Hal ini tentu mempengaruhi ambang batas pendengaran mereka apabila terpapar intensitas suara mesin secara terus-menerus. Upaya yang dapat dilakukan untuk perlindungan diri dari efek kebisingan di ruangan bagian finishing PT. Pundi Indokayu Industri yaitu dengan menggunakan alat pelindung diri berupa earplug untuk pekerja yang berada di ruang finishing, agar dapat mengurangi resiko gangguan kesehatan berupa keluhan pendengaran yang dialami pekerja.

\section{Uji Statistik}

Hasil uji statistik menggunakan regresi sederhana diperoleh hasil intensitas suara $\mathrm{p}=0,178>\alpha(0,05)$, dan masa kerja $\mathrm{p}=0,806>\alpha(0,05)$. Artinya tidak ada hubungan antara intensitas suara dan masa kerja dengan keluhan pendengaran pekerja finishing PT. Pundi Indokayu industri Kecamatan Kalibagor Kabupaten Banyumas.Hasil uji statistik menggunakan regresi ganda hasil $\mathrm{p}=0,178>\alpha(0,05)$, dan masa kerja $\mathrm{p}=0,416>\alpha(0,05)$, sehingga diketahui intensitas suara dan masa kerja tidak berpengaruh terhadap keluhan pendengaran pekerja finishing PT. Pundi Indokayu industri Kecamatan Kalibagor Kabupaten Banyumas

Berdasarkan Peraturan Menteri Tenaga Kerja Nomor 13 tahun 2011 Tentang Nilai Ambang Batas Faktor Fisika dan Faktor Kimia di Tempat Kerja intensitas suara $85 \mathrm{dBA}$ waku pemajanan per hari selama 8 jam.

Tidak adanya hubungan antara intensitas suara dengan keluhan pendengaran terjadi karena titik kerja para pekerja yang berpindah-pindah selama bekerja, intensitas suara mesin yang diukur hanya selisih 1-2 dBA dari standar 85dBA, dan tidak adanya hubungan masa kerja dengan keluhan pendengaran karena para 
pekerja masih berusia produktif dan masa kerja paling lama yaitu 36 bulan.

\section{SIMPULAN}

Hasil analisis regresi sederhana jenis variabel intensitas suara diperoleh hasil $\mathrm{p}=0,178$ $>\alpha(0,05)$, dan masa kerja $p=0,806>\alpha(0,05)$, artinya tidak ada hubungan antara intensitas suara dan masa kerja dengan keluhan pendengaran pekerja finishing PT. Pundi Indokayu Industri Kecamatan Kalibagor Kabupaten Banyumas.

Hasil uji lanjutan menggunakan analisis regresi ganda jenis variabel intensitas suara diperoleh hasil $\mathrm{p}=0,178>\alpha(0,05)$, dan masa kerja $p=0,416>\alpha(0,05)$, sehingga diketahui intensitas suara dan masa kerja tidak berpengaruh terhadap keluhan pendengaran.

\section{SARAN}

1. Pemisahan sumber bising dari pekerja misalnya meletakkan generator di tempat yang terpisah dari para pekerja bekerja, melakukan perawatan mesin secara rutin.

2. Pemasangan peredam suara seperti, Acourete Fiber dan Acourete Board 230.

3. Sebaiknya pekerja finishing PT. Pundi Indokayu Industri dilengkapi dengan ear muff atau earplug, agar dapat mengurangi resiko gangguan kesehatan berupa keluhan pendengaran yang dialami pekerja.

4. Untuk penelitian selanjutnya diharapakan pengukuran keluhan pendengaran, peneliti menggunakan alat audiometri, agar hasil data yang didapatkan lebih valid.

\section{DAFTAR PUSTAKA}

Afif Ma'rifatuluthfi , 2015.Studi Intensitas Suara Di

Bagian Produksi PT. Raja Besi Semarang:

Politeknik Kesehatan Kemenkes Semarang

Jurusan Kesehatan Lingkungan

Purwokerto

Anies, 2005 Penyakit Akibat Kerja. Jakarta : PT. Elex Media Komputerindo

Aris Santjaka, 2011, Statistik untuk Penelitian Kesehatan, Yogyakarta : Nuha Medika
Budiman Chandra, 2007, Pengantar Kesehatan Lingkungan, Jakarta : Penerbit Buku Kedokteran EGC

Budiono, I. 2007. Faktor Risiko Gangguan Fungsi Paru Pada Pekerja Pengecatan Mobil (Studi pada Bengkel Pengecatan Mobil di Kota Semarang). Tesis. UNDIP. Semarang

Budiono, Sugeng A.M, 2009, Bunga Rampai Hiperkes dan KK, Semarang :

UNDIP

Cecep Triwibowo dan Mitha Erlisya Puspahandani, 2013 Kesehatan Lingkungan dan K3. Yogyakarta : Nuha Medika

Ekasanti Widhiaputri, 2013, Studi Tentang Intensitas Suara Dan Upaya Pengendaliannya Pada Ruang Turbin Di PT. Indonesia Power UBP Mrica Banjarnegara : Politeknik Kesehatan Kemenkes Semarang Jurusan Kesehatan Lingkungan Purwokerto

Harmadji, Sri dan Heri Kabullah. 2004. Noise Induced Hearing Loss in Steel Factory Worker. Journal Vol.4 No. 4 . Folia Medica Indonesia, Surabaya

Indah Kusumawati, 2012. Hubungan Tingkat Kebisingan di Lingkungan Kerja Dengan Kejadian Gangguan Pendengaran Pada Pekerja PT X : Universitas Indonesia Fakultas Kesehatan Masyarakat Program Studi Kesehatan Masyarakat

Loblaby F Heinse, Ricky C Sondakh, Johan Johephus, 2013. Hubungan Antara Tingkat Kebisingan Dengan Gangguan Pendengaran Pada Pekerja Bagian Produksi Di PT Pertamina RU VII KasimSorong : Universitas Sam ratulangi Manado Fakultas Kesehatan Masyarakat

Mieke Wahyu Wijayanti, 2014, Hubungan Intensitas Kebisingan Dengan Penurunan Ambang Dengar Pada Tenaga Kerja Di Pt. Putri Indah Pertiwi Desa Pule, Gedong, Pracimantoro, Wonogiri : Universitas Muhamadiyah Surakarta Program Studi 
Kesehatan Masyarakat Fakultas Ilmu Kesehatan

Purwaningtyas Bayu Friandini, 2015. Hubungan Intensitas Suara Mesin Penggilinagn Padi Dengan Keluhan Gangguan Pendnegaran Pekerja Di Desa Kuripan Kecamatan KesugihannKabupaten Cilacap : Politeknik Kesehatan Kemenkes Semarang Jurusan Kesehatan Lingkungan Purwokerto

as Penanggulangan Gangguan Pendengaran dan Ketulian, Jakarta

Suma'mur, PK. 1994 Keselamatan Kerja dan Pencegahan Kecelakaan . CV Haji Massagung. Jakarta

Suma'mur, PK. 2009. Higiene Perusahaan dan Kesehatan Kerja (HIPERKES). CV. Sagung Seto. Jakarta.

Sunarti, Haryati. Konsep Pengaturan Lingkungan Kerja. Februari 2008.

Tri Cahyono, 2014. Pedoman Penulisan Proposal Peneliti Dan Karya Tulis Ilmiah/Skripsi (Edisi Revisi Ketiga): Politeknik
Mukono, 2006, Prinsip Dasar Kesehatan Lingkungan Edisi Kedua, Surabaya Airlangga University Press

Soeripto M, 2008, Higiene Industri, Jakarta : Fakultas Kedokteran UI

Soetjipto, Damayanti. 2007. Gangguan Pendengaran dan Ketulian. Komn

Kesehatan Kemenkes Semarang Jurusan Kesehatan Lingkungan Purwokerto

Yulianto, 2003, Kebisingan dan Getaran. Buletin Kesehatan Lingkungan dan Masyarakat No. 79 dan 80 Tahun XXI Januari 2003, Purwokerto : Departemen Kesehatan Replubika Indonesia Politeknik Kesehatan Semarang Jurusan Kesehatan Lingkungan. 